\title{
Numerical back-analysis of highwall instability in an open pit: a case study
}

\author{
JM Kabuya École Polytechnique de Montréal, Canada \\ R Simon École Polytechnique de Montréal, Canada \\ J Carvalho Golder, Canada \\ D Haviland Golder, Canada
}

\begin{abstract}
In this paper, a numerical modelling study to back analyse a highwall instability event in an open pit has been completed. The unstable highwall was over $125 \mathrm{~m}$ high and $200 \mathrm{~m}$ wide. The overall slope angle was $44^{\circ}$. The highwall instability was detected by slope stability radar and resulted in a multi-bench failure consisting of approximately 3,000,000 $t$ of rock. This highwall's failure provided the opportunity to develop an understanding of the mechanisms and key sensitivities involved with a failure of this magnitude. Using a combination of pre-and post-failure pit scans, the failure scarp was approximated and numerical models were developed and calibrated to simulate the event using SLIDE3 as the primary tool. The first model simulated isotropic rock mass strengths, without incorporation of directional weakness along the predominant orientations of discontinuities. We introduced successively directionally-dependent strength of the jointed rock mass and elevation-dependent foliation dip to confirm the failure surface. Once the failure surface was confirmed, the strength of the structures was reduced, and groundwater pressures were introduced to reach a Factor of Safety approaching the critical target of 1.0. To effectively simulate the highwall's failure, the sub-horizontal joint set was weakened to initiate toe breakout. Subsequently, a section through the failure mass was analysed using RS2 finite element modelling software to explore the possibility of failure mechanisms not simulated in SLIDE3's limit equilibrium calculation. While similar Factors of Safety (or shear strength reduction factors) were produced in the calibrated RS2 and SLIDE3 models using similar inputs assumptions, the significant differences in the two approaches must be considered. While significant uncertainties and opportunities for further study exist, the results of this simple calibration study were judged to reproduce the observed failure mechanism satisfactorily and may be referenced for future geotechnical design analyses for the open pit studied and other pits at the mine site where similar geotechnical conditions or features exist. The back-analysis highlights that understanding the geological variability associated with complex structural environments requires an excellent understanding of the orebody genesis and the regional geologic environment. Local orientations of discontinuity sets can have a significant effect on slope design and are often difficult to predict. The structural sets can be broadly defined but sensitivity analyses on the critical structural orientations should be completed, and continuously monitored as more data become available and during the mine development.
\end{abstract}

Keywords: open pit, back-analysis, limit equilibrium method, finite element method, slope stability radar

\section{Introduction}

The design of mining slopes is dictated by the behaviour of the rock mass which depends on its mechanical properties. However, it is very difficult to directly determine the mechanical properties of rocks at a scale applicable to slope design because the in situ tests are difficult to perform and are expensive. The retro-analysis of a slope failure occurring can then be used as an alternative solution (Coggan et al. 1998; Duncan \& Wright 2005; Martin \& Carew 1986; Wyllie \& Mah 2004). The objectives of the back-analysis are to investigate the underlying mechanisms and rock mass conditions which led to the instability of the slope and to calibrate a set of modelling inputs (rock mass mechanical parameters) which reproduce the observed 
failure mechanism. The calibrated model should produce a Factor of Safety (FoS) approaching the critical target of 1.0 while matching the observed extents of deformation/failure and the controlling mechanisms of the instability. Where measured slope deformation is tied to known physical changes (e.g. stages of mining advance, groundwater fluctuations, seismic events), simulated deformation magnitudes may also be calibrated in an appropriate numerical model. The results of the calibration can then be used for establishing remediation design or may be referenced, where relevant, in future engineering design analyses where similar conditions exist.

In this paper, we carry out a numerical modelling study to back-analyse a highwall instability event which occurred in an open pit in Canada. The unstable highwall was over $125 \mathrm{~m}$ high and $200 \mathrm{~m}$ wide. The overall slope angle was $44^{\circ}$. This highwall's failure provided the opportunity to develop an understanding of the mechanisms and key sensitivities involved with failure of this magnitude. The instability in the open pit studied was identified in 2017 in the southeast highwall, consisting predominantly of a mass of foliated quartzite (QR) bounded by contacts with a more competent iron formation (IF) exposed on the pit wall. Photographs (such as Figure 1) show that a series of single to double bench scale wedge failures had developed on or near these QR-IF contacts prior to the main failure event, indicative of the low strength and unfavourable orientation of these structures (QR foliation and QR-IF contacts) relative to the pit wall. Kabuya \& Henriquez (2017) completed a review of the instability in late 2017 and issued a memorandum summarising their findings, in which recommendations were made for engineering controls to limit the impact of a potential highwall failure. These controls included increased slope monitoring which incorporated movement trigger warnings and conducting a slope stability assessment prior to continuation of mining beneath the toe of the failure. In July 2018, the initial instability progressed into a multi-bench failure containing an estimated 3,000,000 t of rock, becoming one of the most significant instability events to have occurred at the mine site (see Figure $1 \mathrm{~b}$ for post-failure photograph).

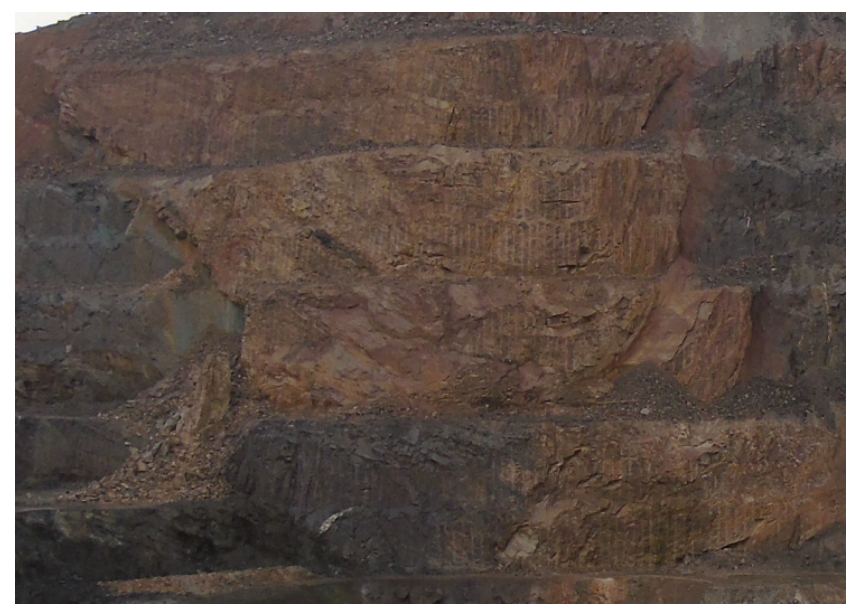

(a)

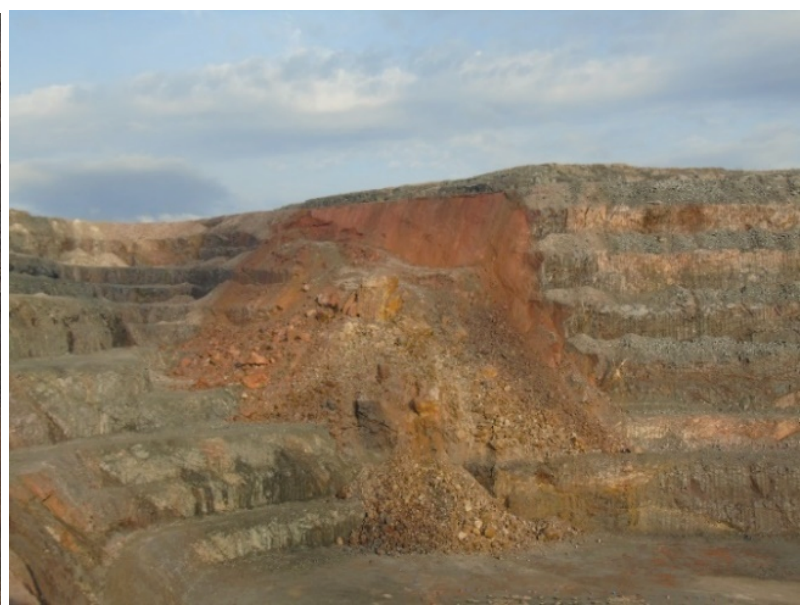

(b)

Figure 1 Southeast highwall: (a) Pre-failure (2018-07-02); (b) Post-Failure (2018-07-05)

A GroundProbe slope stability radar detected the slope acceleration exceeding trigger warning levels prior to the ultimate collapse, including detection of a smaller failure preceding the main event along the eastern boundary on 4 July. The radar monitoring system and trigger warning levels set by the mine were thus considered to be effective for their purpose, having provided sufficient warning of the imminent collapse to allow for the evacuation of personnel and equipment from the area.

The next sections present the back-analysis methodology and tools; modelling inputs and assumptions; and a summary and discussion of the modelling results. 


\section{Back-analysis methodology}

Our approach to back-analysing the highwall instability involved three steps:

1. Step 1: Base case modelling. Base case stability models were developed using SLIDE3 3D limit equilibrium slope stability analysis program (Rocscience Inc. 2019a). Computerised limit equilibrium methods are widely used in the mining industry for slope stability analysis, often favoured for their advantages of relatively straightforward model development and rapid computation times. However, limitations and inherent assumptions of the limit equilibrium method must be considered (discussion around the applicability of the limit equilibrium method to this highwall instability event is provided below). Inputs to the base models represented an estimate of the geomechanical and hydrogeological conditions relevant to the instability based on prior characterisation and data collection. The results of the base models were reviewed critically against the characteristics of the observed instability, to guide the iterative calibration which would follow.

2. Step 2: Iterative calibration of the base case model to reproduce the observed failure characteristics. Calibration was performed by incrementally adjusting modelling inputs within reasonable limits until a satisfactory replication of the observed failure conditions was achieved. Parameters to be adjusted in calibration were selected using our judgement, considering uncertainty (well-defined parameters were not targeted for calibration) as well as the intended calibration effect on stability and failure mechanisms.

3. Step 3: Finite element back-analysis modelling. A 2D section through the failure mass was also analysed in Rocscience's RS2 (Rocscience Inc. 2019b) finite element modelling software. Although the $2 \mathrm{D}$ section represents a simplification of the geometry of the pit, the failure mass, and relevant geological formations, the finite element simulation allows for a more complete analysis of the deformation mechanisms likely involved in the failure than the 3D limit equilibrium model, including elastoplastic rock mass response and yielding or separation of discrete joints within, surrounding, and bounding the failure (Jing 2003; Stead et al. 2006). The purpose of modelling in RS2 was to verify the results of SLIDE3, though the significant geometric differences between the 2D and 3D models must be considered. Comparison of geometrically equivalent 3D finite element and limit equilibrium models would have been more informative, but the development of a 3D finite element model was not feasible within the time constraints of this study.

Rocscience's SLIDE3 3D limit equilibrium slope stability analysis program was selected as the primary tool for back-analysing the open pit highwall failure. 3D limit equilibrium analysis (in comparison to 2D) allows for the full incorporation of the complex geology and geometry of the pit wall, as well as the true relative orientations of structural features and weak planes contributing to the failure. As indicated above, the development of limit equilibrium models is relatively straightforward in comparison to other 3D modelling methods, in large part because discretisation (meshing) of the slope and rock mass is not required. Although widely used for the analysis of mine slopes, the limit equilibrium computation itself is a simplification of more rigorous stress-deformation modelling approaches which perform more complete simulation of the physical behaviour of the rock mass. In this case, the geometry of the highwall failure mass, which was situated on a convex 'nose' of the pit wall and should have thus experienced minimal lateral confining stress, was considered relatively amenable to the simplified limit equilibrium analysis. In contrast, failure of a tightly concave highwall would be more strongly influenced by lateral confinement and may be better represented by 3D stress-deformation modelling (Martin \& Stacey 2018), though this would result in more time-consuming model development.

\section{$3 \quad$ Base modelling inputs}

Data sources and assumptions in the preparation of the base (pre-calibration) modelling inputs for the highwall failure back-analysis are presented in this section. As part of the calibration process, some of these inputs were subsequently modified to better simulate the observed failure characteristics. 


\subsection{Open pit geometry and mining sequence}

A series of 3D topography surfaces representative of the highwall geometry at the time of failure as well as the progression of mining leading from a stable to an unstable state were used in the numerical back-analysis. The following surfaces were modelled:

- 2015-12-01 topography surface: Pit floor at $686 \mathrm{~m}$ elevation in the area of the highwall instability.

- 2017-01-01 topography surface: Pit floor at $644 \mathrm{~m}$ elevation in the area of the highwall instability.

- 2018-07-05 topography surface: High-resolution topography scan immediately prior to the main failure event. Pit floor at $623 \mathrm{~m}$ elevation in the area of the highwall instability.

In RS2, to simulate the stress path from a pre-mining state to the conditions immediately preceding the failure, a topography surface representing the pre-mining terrain was also included. In both SLIDE3 and RS2, the post-failure high-resolution topography scan was referenced as an indication of the failure extents in the upper portion of the slope, where a well-defined failure scarp is exposed.

\subsection{Geological model}

The mine geological block model was used as the basis for developing 3D geology solids to be used for back-analysis modelling. The 3D geology solids developed were compared on a series of sections through the area relevant to the instability event and were found to be in close agreement. These 3D solids files were clipped to the area of interest for SLIDE3 import and sectioned for use in RS2. Figure 2 depicts the geometrical model (2018-07-05 topography surface) including the geological model used in the initial iteration of the base case model. Five rock lithological units are present in the southeast area of the open pit studied: QR, IF, amphibolite (AMP), gneiss (GN) and quartz rock mica schist (QRMS).

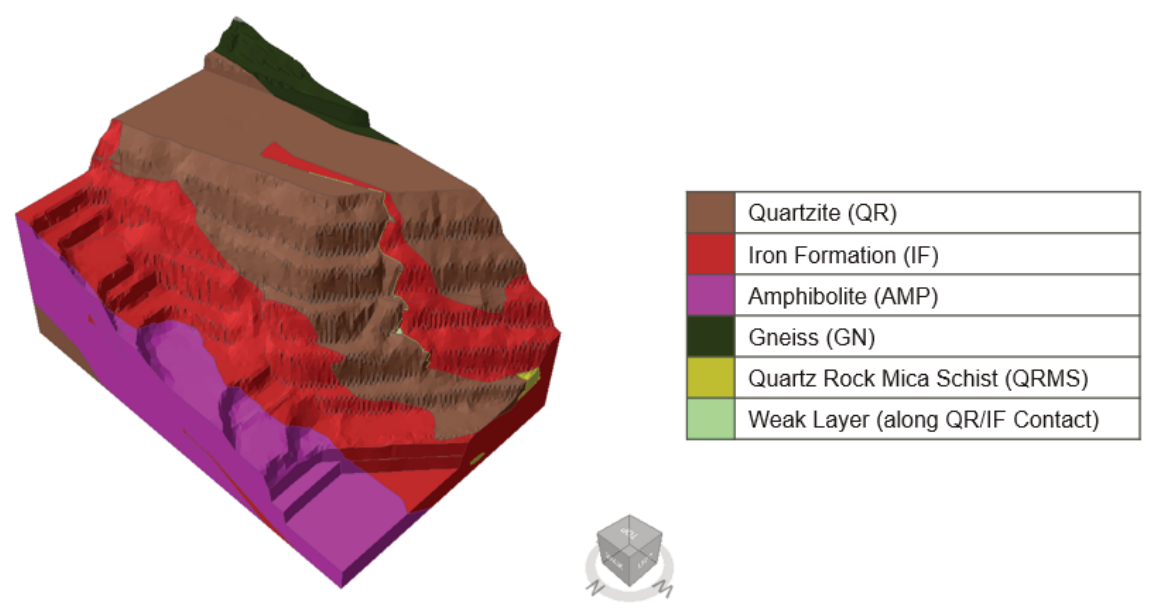

Figure 2 Geometrical model including the geological model

\subsection{Geotechnical model}

A previous geotechnical characterisation for the open pit (Piteau Associates Engineering Ltd 2016), as well as data presented in Kabuya \& Henriquez (2017) specific to the highwall failure location, have been used for the development of base case material parameters for back-analysis modelling. The above reports were reviewed to determine the geotechnical parameter inputs most relevant to back-analysis study. The following sections provide discussion around the sources and derivation of the base case modelling input parameters for the SLIDE3 and RS2 models.

\subsubsection{Rock mass strength}

Base case rock mass strength and quality parameters for the various rock units have been sourced from reported $35^{\text {th }}$ percentile strength parameters used for $2 \mathrm{D}$ limit equilibrium analyses by Piteau Associates 
Engineering Ltd (2016), presented in Table 1. The strength of all rock units has been approximated by fitting the modified Hoek-Brown failure criterion (Hoek et al. 2002). The properties presented in Table 1 were used as the input parameters for the base case finite element and limit equilibrium numerical models.

For simplicity, initial models were run considering the above rock mass strengths as isotropic, without incorporating potential variation in directional strength due to predominant orientations of joints or foliation. Anisotropic strengths were considered in subsequent model runs, whether implicitly in the modelled rock mass strength, explicitly in the form of specific defined joints or weak surfaces, or both. The base case model rock mass strengths incorporated a disturbance factor (D) of 0.7 representative of 'good' blasting control (Hoek et al. 2002). Site photographs from the area of the failure indicate well-controlled blasting likely resulting in only modest rock mass damage ('half barrels' from perimeter trim blastholes are visible on the final walls). However, stress relief can be expected to contribute to disturbance, particularly given the convex slope geometry in the area of the failure. The disturbance factor of 0.7 thus considered appropriate and was applied to the entire slope/rock mass, given its limited extent beyond the area of interest. Based on the observed failure extents, it is likely that the entirety of the failure mass (at least) was affected to some degree by stress relief prior to instability.

Table 1 Hoek-Brown rock mass strength parameters

\begin{tabular}{lllll}
\hline Lithology & $\begin{array}{l}\text { Unit weight } \\
\left(\mathbf{k g} / \mathbf{m}^{\mathbf{3}}\right)\end{array}$ & $\begin{array}{l}\text { Intact rock } \\
\text { strength (MPa) }\end{array}$ & RMR $_{76} / \mathbf{G S I}$ & Mi \\
\hline Amphibolite & 3,066 & 93 & 71 & 11 \\
Gneiss & 2,835 & 56 & 65 & 23 \\
Iron formation & 3,583 & 150 & 73 & 25 \\
Quartzite & 2,651 & 258 & 78 & 33 \\
Quartz rock mica schist & 2,674 & 113 & 70 & 12 \\
\hline
\end{tabular}

\subsubsection{Orientations of discontinuities}

Kabuya \& Henriquez (2017) provided more specific commentary on the structural interpretation of the immediate area of highwall instability. The structural data were collected from photogrammetry mapping of the unstable highwall. Figure 3 presents a stereonet representative of the discontinuity sets and orientations. Discontinuities along foliation in the region of the failure are typically moderately to steeply dipping with strike near-parallel to northwest-facing pit wall (FL-1B, FL-1C, and FL-1A). Cross joints oriented orthogonally to the foliation are also present (JN Set 1A/1B, BD-1). Photos in Kabuya \& Henriquez (2017) indicate that the dip of the foliation may flatten and become progressively shallower with increasing pit depth in the immediate area of the failure, which was investigated further in model calibration.

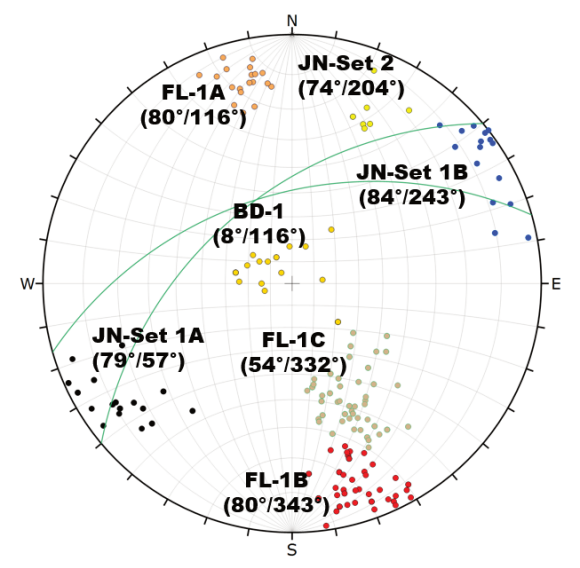

Figure 3 Structural interpretations of the southeast region of the open pit (Kabuya \& Henriquez 2017) 


\subsubsection{Shear strength along discontinuities}

Anisotropic shear strengths assumed for faults, joints and bedding joints (discontinuities along foliation) which were used in prior 2D limit equilibrium analyses for the mine were summarised by Piteau Associates Engineering Ltd (2016). These strengths represent a blending of the estimated rock mass strengths (as described in 3.3.1) and discontinuity strengths from laboratory direct shear testing. The blending of strengths is justified on the basis that a slip surface-even when aligned in the general orientation of joints or foliationis unlikely to exploit interconnected discontinuities along its entire surface area. The shear surface must 'bridge' through portions of the rock mass. For back-analysis modelling of the highwall failure, where photos have indicated highly persistent foliation discontinuities, strengths based on $5 \%$ rock bridging have been assumed for the orientations of bedding joints and other joints in base case models. These strength parameters are summarised in Table 2 for discontinuities in AMP, IF, and QR. No faults are expected to have influenced the highwall failure to our knowledge, however, the ostensibly weak geological contact between QR and IF which formed a large portion of the failure surface was assigned reduced strength parameters associated with QR faults and 5\% rock bridging (refer to Table 2 ) for base case modelling. Residual strength parameters for use in RS2 models were based on the ratio of residual strength to peak strength in direct shear test results ( $35^{\text {th }}$ percentile summary) reported by Piteau Associates Engineering Ltd (2016). A ratio of 0.79 was indicated from the $35^{\text {th }}$ percentile direct shear tests from all rock units, which was approximately matched in the residual friction angles listed below, rounded to the nearest whole number. Residual cohesion was assumed to decrease to zero.

Table 2 Mohr-Coulomb shear strength based on lithology and discontinuity type (5\% rock bridging adapted from Piteau Associates Engineering Ltd 2016)

\begin{tabular}{|c|c|c|c|c|c|}
\hline Lithology & $\begin{array}{l}\text { Discontinuity } \\
\text { type }\end{array}$ & $\begin{array}{l}\text { Cohesion } \\
(\mathrm{kPa})\end{array}$ & $\begin{array}{l}\text { Friction } \\
\text { angle }\left({ }^{\circ}\right)\end{array}$ & $\begin{array}{l}\text { Residual } \\
\text { cohesion (kPa) }\end{array}$ & $\begin{array}{l}\text { Residual } \\
\text { friction angle }\left({ }^{\circ}\right)\end{array}$ \\
\hline \multirow[t]{3}{*}{ Amphibolite } & Fault & - & 22.6 & - & 18.0 \\
\hline & $\begin{array}{l}\text { Bedding joint } \\
\text { (foliation) }\end{array}$ & 128 & 33.6 & 0 & 27.0 \\
\hline & Joint & - & 39.1 & - & 33.0 \\
\hline \multirow[t]{3}{*}{ Iron formation } & Fault & - & 24.3 & - & 20.0 \\
\hline & $\begin{array}{l}\text { Bedding joint } \\
\text { (foliation) }\end{array}$ & 154 & 35.0 & 0 & 29.0 \\
\hline & Joint & - & 40.3 & - & 34.0 \\
\hline \multirow[t]{3}{*}{ Quartzite } & Fault & - & 25.4 & - & 20.0 \\
\hline & $\begin{array}{l}\text { Bedding joint } \\
\text { (foliation) }\end{array}$ & 283 & 35.9 & 0 & 30.0 \\
\hline & Joint & - & 41.1 & - & 34.0 \\
\hline
\end{tabular}

\subsection{Hydrogeological model}

Two piezometers are located in the vicinity of the highwall failure but are far enough away that they do not effectively directly track the groundwater conditions within the failure mass and along its bounding surfaces. Readings taken from piezometers between 15 September 2015 and 5 September 2018 show significant fluctuation in groundwater levels, with the peak measurements indicating groundwater levels essentially even with ground surface at the piezometer locations. Closer to the failure, groundwater conditions will be significantly affected by drainage into the pit. A photo (Figure 4a) shows ice formation on the pit walls surrounding the mass that eventually failed. Interestingly, though ice formation is evident on both sides of the failure, there appears to be minimal drainage through the failure mass itself. While judging groundwater 
conditions based on observed drainage on the slope surface is highly uncertain, the lack of drainage through the failure mass may be interpreted as a result of the groundwater flow encountering conductive features around the perimeter of the failure. While this suggests that much of the failure mass itself may be dry, pore pressure along bounding features and near the toe of the failure may still have contributed to the instability. An additional photo presented in Figure 4b, taken on 1 July 2018, shows the post-thaw conditions of the slope. Dark colouration on the rock mass suggests the presence of groundwater surrounding the failure mass extending to the crest of the slope while the failure mass itself is mostly dry, consistent with the interpretation of Figure $4 a$.

Base case models in SLIDE3 and RS2 were initially generated with dry groundwater conditions (i.e. no groundwater table). Considering the discussion above, later model iterations incorporated groundwater pressures in the bounding QR-IF contact and the QR and IF rock mass at the toe of the failure mass.

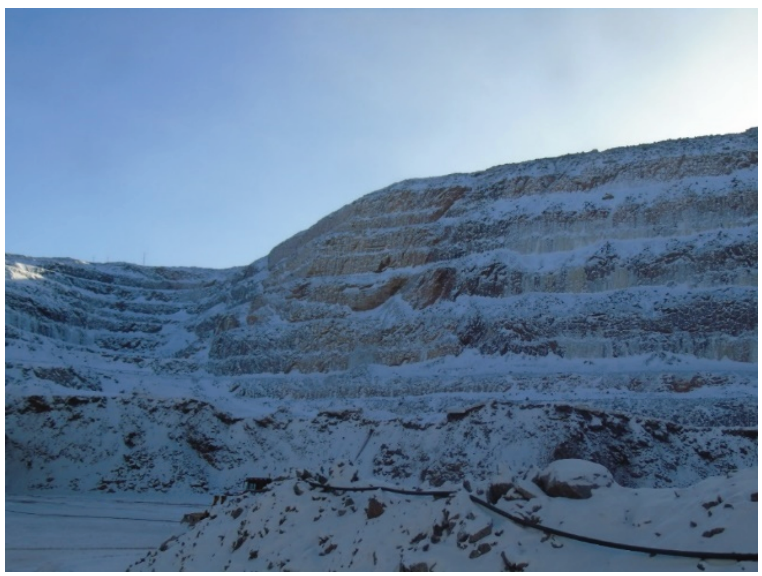

(a)

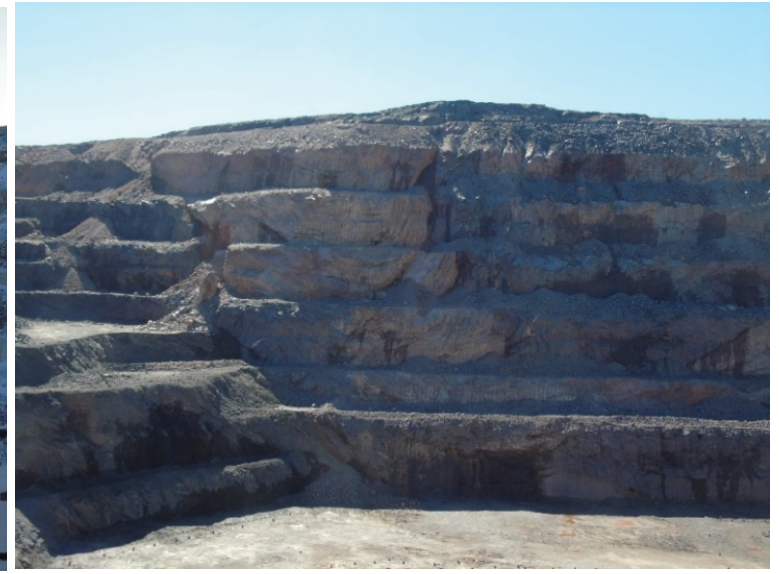

(b)

Figure 4 (a) Ice formation due to groundwater drainage surrounding the failure mass; (b) Post-thaw conditions of the slope surrounding the failure mass

\subsection{Data from slope stability radar}

Following the identification of the instability risk in the open pit but prior to the highwall failure event, slope movement monitoring was established in the area of concern using a GroundProbe SSR (slope stability radar) unit. The purpose of the radar was to track the movement of the slope and to provide warning of any acceleration which could indicate imminent failure. For the purposes of this back-analysis study, the data collected by the radar system and summarised in GroundProbe (2018) were reviewed for potential insight into the progression, extents, and mechanism of the failure. According to the summary by GroundProbe, the SSR system detected a period of zero deformation between 17 and 20 May, followed by linear, stable creeping behaviour in the region of concern between 20 May and 30 June 2018. GroundProbe's back-analysis concluded that 30 June marked the onset of progressive failure, which continued until the eventual multi-bench failure at 16:40 on 5 July 2018 (Figure 5). Trends were analysed for pixel $(63,16)$ which exhibited the highest deformation and velocity magnitudes. The pixel $(63,16)$ size is $4.20 \times 4.13 \mathrm{~m}$. Accumulated deformation reached $253 \mathrm{~mm}$ prior to the failure, velocity increased from $\pm 0.25 \mathrm{~mm} / \mathrm{h}$ to $\pm 8 \mathrm{~mm} / \mathrm{h}$, and inverse velocity decreased from $\pm 4.0 \mathrm{~h} / \mathrm{mm}$ up to $\pm 0.125 \mathrm{~h} / \mathrm{mm}$ (GroundProbe 2018). Figure 6 shows the slope movement data collected by the radar system just prior to the main failure event on 5 July.

As the GroundProbe radar monitors only surface displacement, it cannot determine the depth of the failure surface into the wall. Photos taken after the failure incident as well as sections comparing the geological model and post-failure 3D scan suggest that a large portion of the upper slip surface corresponds with the contact between the QR failure mass and the underlying IF. Lateral and vertical extents of the failure can be interpreted from the GroundProbe data, which indicate the failure mass was constrained by the QR/IF contact or weakened rock near the contact on the west, and also on a portion of its eastern extents. The 4 July small wedge failure occurred along the eastern QR/IF contact. 


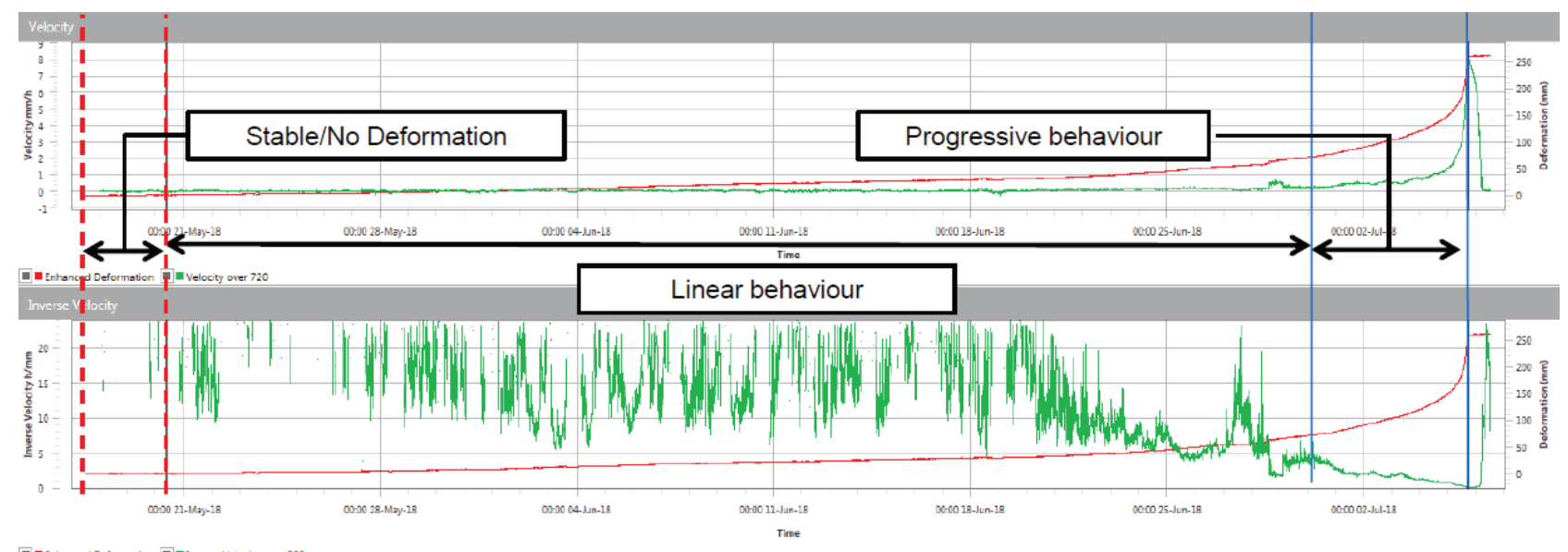

Figure 5 Sequence of highwall behaviour (GroundProbe 2018)
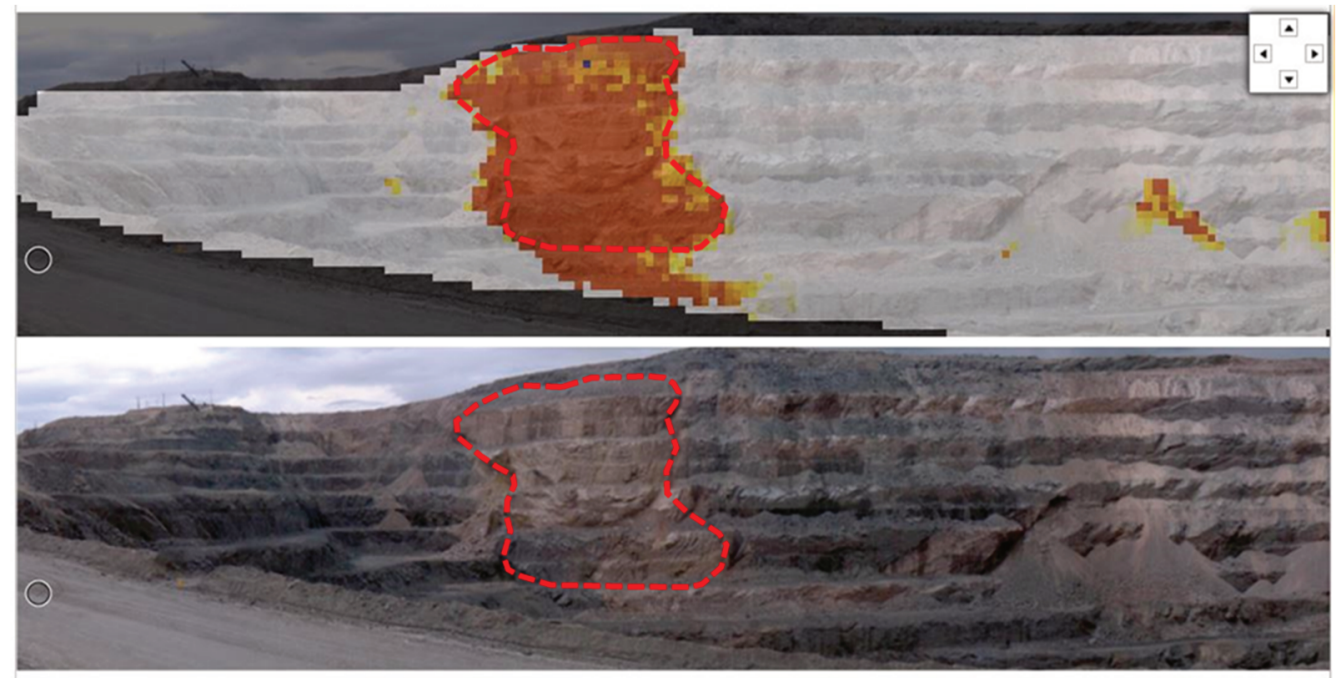

Figure 6 Slope movement area detected by GroundProbe radar prior to the 5 July main failure event

The precise toe 'breakout' elevation of the failure is unknown, as it remains covered by the broken rock which has run out from the failure. Based on the GroundProbe data, movement was detected prior to failure extending below the $600 \mathrm{~m}$ elevation bench which features a wide step-out. Photos and scans taken post-failure suggest that this bench did not fail. The movement detected by the GroundProbe may have been related to other interference (talus ravelling) or misalignment. Based on available data, it is expected that the toe of the failure did not extend below $615 \mathrm{~m}$ elevation, though the area remains buried in the failure run out.

\section{$4 \quad$ SLIDE3 limit equilibrium back-analysis modelling}

Rocscience's SLIDE3 3D limit equilibrium slope stability modelling program was the primary tool for back-analysing the open pit highwall failure. In SLIDE3, the potential sliding mass is divided into vertical columns for analysis. An overall FoS for the sliding mass is calculated based on the forces and moments acting on each column and this calculation is performed iteratively to search for the most critical potential failure surface, i.e. the slip surface with the lowest overall FoS (Janbu 1973).

\subsection{SLIDE3 model development}

The base case SLIDE3 model was developed progressively, beginning with an assumption of homogenous, isotropic rock units and incrementally introducing anisotropic strengths and discrete structures based on the 
input parameter assumptions in Section 3. Complexity was added gradually to the models, to understand the effects of each assumption on the stability analysis. The development and results of the base model (prior to calibration of strength parameters) are discussed below. In all cases, reported minimum FoSs were determined using the Janbu simplified force-equilibrium method and a Cuckoo search for ellipsoidal surfaces followed by surface altering optimisation.

\subsubsection{Base model (V1)}

The geometrical model including the geological model used in the initial iteration of the base case model was depicted in Figure 2. The first model simulated isotropic rock mass strengths according to Section 3.3, without incorporation of directional weakness along the predominant orientations of discontinuities. The contact between QR and IF which appears to have formed a significant portion of the upper failure surface was assigned $Q R$ foliation strength parameters assuming 5\% rock bridging (cohesion $=283 \mathrm{kPa}$, friction angle $=35.9^{\circ}$ ), making it weaker than the surrounding rock. Dry groundwater conditions were assumed. The results of the isotropic rock mass model indicated that the slope was stable (minimum FoS $=6.5$ ), suggesting that the estimated rock mass strengths alone do not effectively simulate the directional weakness which can control stability when persistent discontinuities are aligned with a direction of potential sliding. Nonetheless, the geometry of the lowest FoS slip surface did match well with the observed extents of the failure as detected by the mine's GroundProbe slope monitoring radar, as shown in Figure 7a (compare to GroundProbe screenshot in Figure 6). Much of the western boundary, as well as the back-sliding plane and the lower east boundary of the minimum FoS surface, were constrained by QR/IF contacts, as expected. The critical surface extended to the $615 \mathrm{~m}$ bench elevation, breaking through IF at the toe, closely matching the interpreted extents of movement detected by the GroundProbe radar immediately prior to the failure (refer to the GroundProbe screenshot in Figure 6). Note that the model results presented in Figure 7a solely depict the extent of the main highwall failure event that took place on 5 July 2018. This scenario excludes the smaller failure that preceded the main event, which took place along the eastern boundary on 4 July 2018 as detected by the GroundProbe SSR.

\subsubsection{Anisotropic strength added (V2)}

With the aim of reducing the slope FoS and to better represent the directionally-dependent strength of the jointed rock mass, anisotropic strength windows representative of the average orientation of Foliation $1 \mathrm{~B}$ and $1 \mathrm{C}\left(67^{\circ} / 338^{\circ}\right)$, and joint sets $\mathrm{JN}-1 \mathrm{~A}\left(79^{\circ} / 57^{\circ}\right)$ and $\mathrm{JN}-1 \mathrm{~B}\left(84^{\circ} / 243^{\circ}\right)$ were added to all rock units in the model, which resulted in a reduced slope FoS of 4.8 . When anisotropic strengths representative of JN-2 $\left(74^{\circ} / 204^{\circ}\right)$ and $\mathrm{BD}-1\left(8^{\circ} / 116^{\circ}\right)$ were also added, FoS was further reduced to approximately 2.7 (Figure $7 \mathrm{~b}$ ).
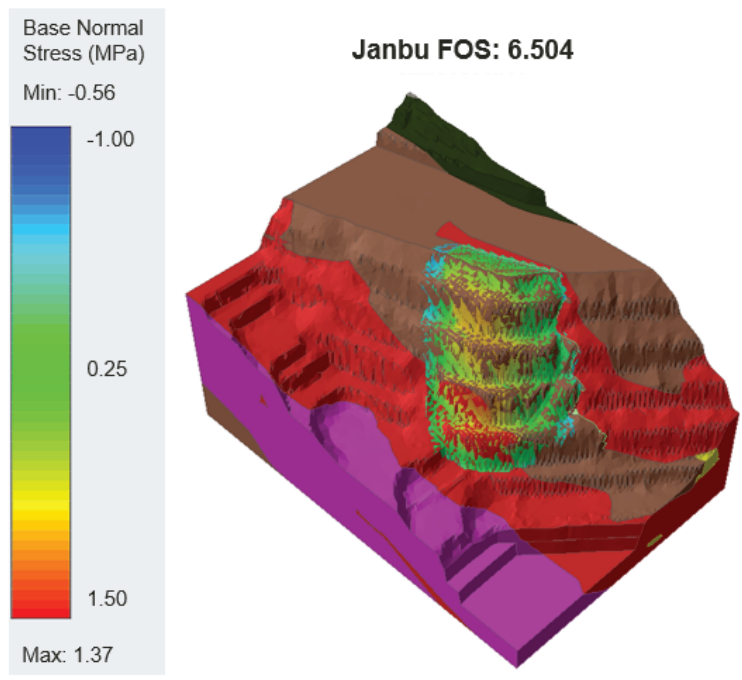

(a)
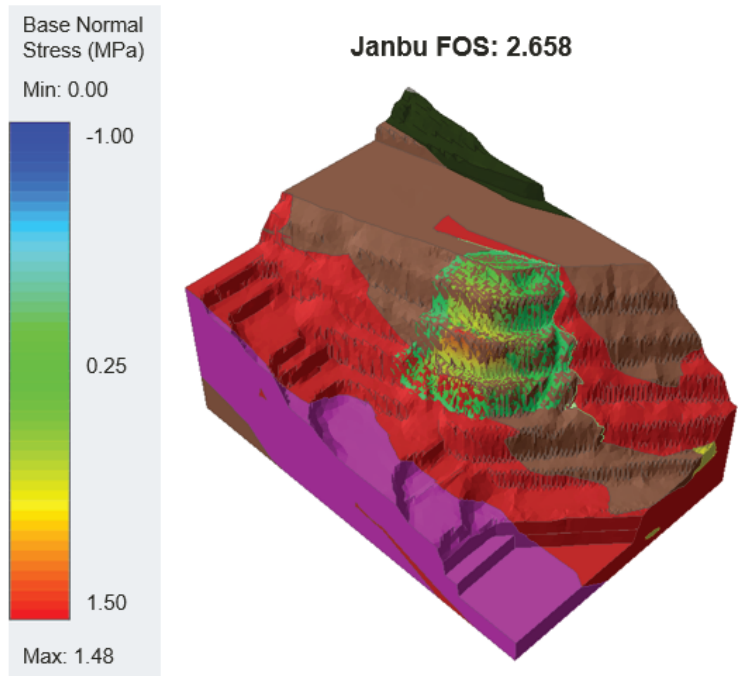

(b)

Figure 7 Critical slip surface: (a) V1 model; (b) V2 model 
In all cases, discontinuity shear strengths ( $5 \%$ rock bridge, Table 2 ) were assigned to anisotropic windows within $\pm 10^{\circ}$ of these average orientations. Unchanged from V1, the primary sliding plane contact between QR and IF was assigned QR foliation strength parameters ( $5 \%$ bridging) and dry groundwater conditions were assumed. Incorporating reduced strength windows based on the dominant joint sets significantly reduced the predicted critical FoS but was not sufficient to trigger failure (minimum FoS 2.7). The vertical extent of the minimum FoS surface also changed, no longer passing through the $615-645 \mathrm{~m}$ bench as indicated by the GroundProbe monitoring data.

\subsubsection{Elevation-dependent foliation (V3)}

To further define the foliation structure present in the immediate area of the highwall instability and in an attempt to adjust the predicted failure geometry, separate structural regimes were defined for the upper and lower slopes in the failure area. A horizontal dividing plane was defined approximately $70 \mathrm{~m}$ below the crest of the pit slope (675 m elevation), with steeply dipping foliation (FL-1B, 80\% $343^{\circ}$ ) above and more shallowly dipping foliation (FL-1C, $54^{\circ} / 332^{\circ}$ ) below. This division was based on annotated photos in Kabuya \& Henriquez's presentation slides on the instability area (Kabuya \& Henriquez 2017). Figure 8a depicts two sections within the V3 limit equilibrium model, denoted by the colour variation in QR. Analysis of the V3 model did not significantly alter the predicted failure geometry from V2 and indicated a slightly increased critical FoS (3.1) (Figure 8a). Despite this, the V3 model was considered the best estimate of the geometric and structural features of the highwall failure. Subsequent calibration of the V3 model was carried out by testing varying strength parameters and groundwater conditions, described in the following section.

\subsection{SLIDE3 model calibration}

A calibration of strength parameters and groundwater conditions was performed on the 2018-07-05 V3 model in order to reduce the estimated FoS to approximately 1.0 and to match the observed extents of failure and interpreted mechanisms of failure (to the extent that such mechanisms can be approximated in a model based on limit equilibrium assumptions). To do so, variations of parameters related to shear strengths, discontinuities, and groundwater conditions were tested as explained below.

Given that the contact between QR and IF forms a significant portion of the upper failure surface, it is of no surprise that its assumed strength parameters have a significant influence on the predicted mechanism and slope FoS. After experimentation, the contact was assigned a reduced friction angle of $25.4^{\circ}$ representative of faults within QR (Piteau Associates Engineering Ltd 2016), and $0 \mathrm{kPa}$ cohesion was assigned based on the assumption that the contact may have previously undergone shearing.

Through experimentation, it was found that, in particular, the instability of the slope is strongly dependent on the inclusion of the sub-horizontal BD-1 joint set at the toe and on its assumed strength parameters. This sensitivity is interpreted to be a result of the failure mechanism. The upper portion of the failure mass slides along the weakened QR-IF contact. However, at the toe of the failure, the slip surface must depart the weak contact and QR foliation, rotating to a shallower-dipping orientation in order to 'daylight' and break through the pit wall. The sub-horizontal BD-1 joint set (modelled with $a+/-10^{\circ}$ anisotropic strength window) provides a weak plane that can be exploited by this lower portion of the failure surface. Tests with varying friction angles for BD-1 $\left(40^{\circ}, 35^{\circ}, 30^{\circ}\right)$ confirmed sensitivity to this parameter, and it was found that a low friction angle $\left(30^{\circ}\right)$ and zero cohesion was required to force the slope FoS to approach and fall below the target of 1.0 (FoS values of 1.11 and 1.04 were predicted in equivalent models with BD-1 friction angles of $40^{\circ}$ and $35^{\circ}$, respectively). The weakened $\mathrm{BD}-1$ parameters $\left(30^{\circ}\right.$ friction, $0 \mathrm{kPa}$ cohesion) represent shear strength only marginally greater than the modelled strength of the weak QR-IF contact, which is continuous and assumed to be altered/infilled and sheared. Thus, it was considered that further downgrading of the BD-1 strengths would be unreasonable without supporting evidence.

The shape of the resulting failure surfaces was found to be dependent on the location in the slope within which the weakened BD-1 parameters were applied. In general, slip surfaces tended to 'break out' at the highest possible elevation where the weakened BD-1 strength could be exploited. To best match the extents 
of slope movement detected by the slope monitoring radar prior to failure, it was necessary to limit the application of the weakened BD-1 parameters to only the IF and QR units at toe of the slope, below $646 \mathrm{~m}$ elevation. Limiting the extent of the weakened BD-1 set to below $646 \mathrm{~m}$ produced a failure mass nearly reaching the expected toe breakout elevation (between 615 and 646 m elevation) with an appropriate FoS. Other test cases run with BD-1 further restricted to lower in the slope did lower the elevation of toe breakout, but also resulted in higher predicted FoS that would have required further downgrading of BD-1 strengths to calibrate. As above, further downgrading of these strengths was considered unreasonable without supporting evidence of such weakness.

The possibility of groundwater presence in the bounding QR-IF weak contact and in the toe of the failure mass was considered. In order to simulate this condition, groundwater pressure based on an Ru coefficient of 0.3 was applied to the QR-IF contact bounding the slip surface and below $646 \mathrm{~m}$ elevation in the IF and QR rock mass. The Ru coefficient of 0.3 simulates pressures representative of a near-surface watertable.

The above parameters and assumptions produced a model with a minimum slope FoS of 0.97 for a failure surface which slides along the weakened QR-IF contact, exiting the slope at a minimum toe elevation of approximately $642 \mathrm{~m}$, exploiting the weakened BD-1 joint set at the toe. Figure $8 \mathrm{~b}$ shows an image of this failure surface. The same model, run without the influence of groundwater, indicated a slope FoS of 1.3. Equivalent models run using the 2015 and 2017 pit topography surfaces produced FoS values of 8.2 and 1.2 under wet conditions (as described above), respectively. This indicates that the pit wall was nominally stable at these earlier pit floor elevations, as expected.

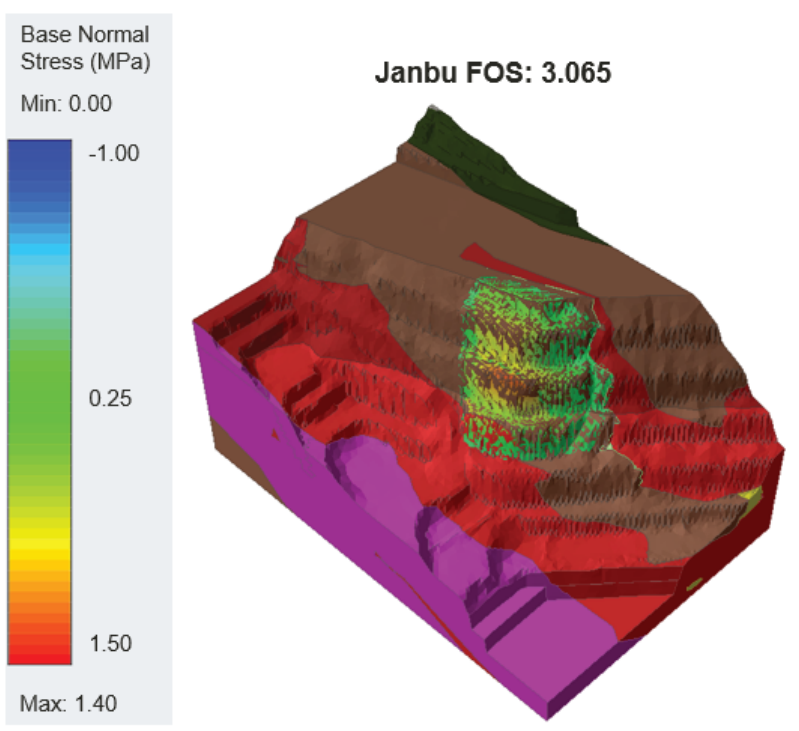

(a)

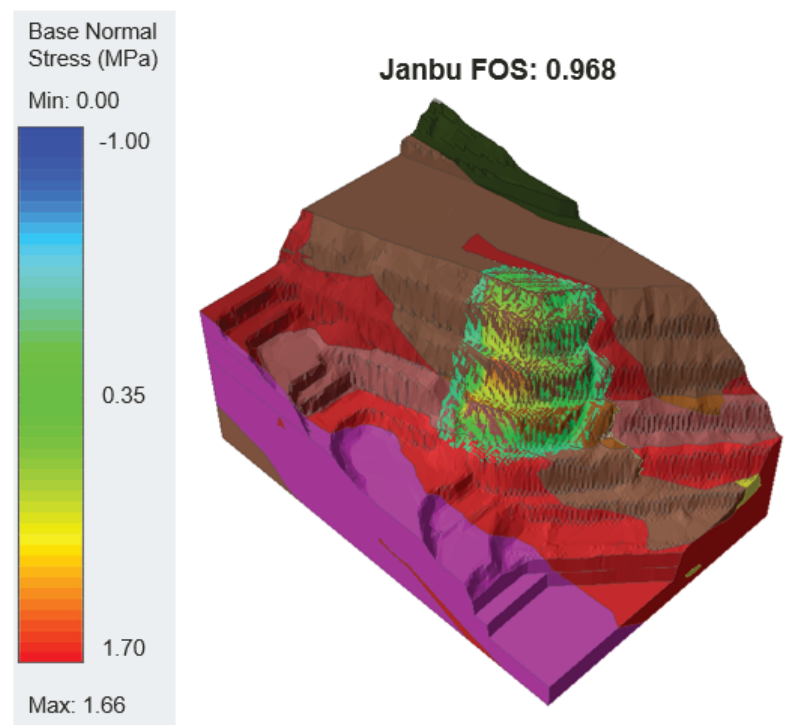

(b)

Figure 8 Critical slip surface: (a) V3 model; (b) Calibrated SLIDE3 model

\section{$5 \quad$ RS2 finite element back-analysis modelling}

\subsection{Introduction}

A section through the highwall failure mass was analysed in RS2 to verify the results of the SLIDE3 modelling exercise and to explore the possibility of failure mechanisms not simulated in SLIDE3's limit equilibrium calculation. In particular, the RS2 assessment focussed on the influence of parameters related to the BD-1 joint set, and strain softening parameters (the reduction in shear strength of joints of rock mass elements once plastic yielding has taken place). The RS2 section was chosen such that it aligned with the interpreted direction of sliding, perpendicular to the predominant $Q R$ foliation (section azimuth $160^{\circ} / 340^{\circ}$ ) and through the centre of the failure mass. By aligning the 2D section in this way, the impact of the geometric 
simplification (reducing the 3D slope to a 2D section) should be minimised but nonetheless, geometric differences must be considered when comparing the $2 \mathrm{D}$ and $3 \mathrm{D}$ model results.

Joint sets orientated perpendicular or near perpendicular to the slope orientation modelled in RS2 (JN-1A, $J N-1 B, J N-2$ ) were excluded from the model which is a necessary simplification for analysis in 2D. In 3D, sets $\mathrm{JN}-1 \mathrm{~A}$ and $\mathrm{JN}-1 \mathrm{~B}$ could influence the slope stability as lateral release features, but $2 \mathrm{D}$ plane strain analysis does not consider these releases (in-plane geometry, including joints, is effectively simulated as infinite in extent into and out of the analysis plane). Only slip along joints intersecting the analysis plane can be simulated in 2D, and the behaviour of joints near-parallel to the plane cannot be simulated. While JN-2 is slightly more oblique to the section plane than sets $1 \mathrm{~A}$ and $1 \mathrm{~B}$, it dips into the pit wall and is not considered to have influenced the slope stability, so was not necessary to include. The weak QR-IF contact was simulated as a discrete joint with fault strength parameters ( $25.4^{\circ}$ friction angle, zero cohesion), unchanged from the calibrated SLIDE3 model. Foliation in the QR and IF rock units was divided into upper and lower domains, with strength parameters and orientations also unchanged from SLIDE3. Foliation planes were also simulated as discrete, continuous joints. The BD-1 joint set was initially excluded from RS2 and later tested with varying strength parameters and representations (i.e. as a network of discrete joints, or using a ubiquitous joint constitutive model), to observe its impact on overall slope stability.

\subsection{Results}

In RS2, the stability of a slope is quantified using the shear strength reduction method. The shear strength reduction method is discussed by several authors and is widely used in slope stability analysis (Dawson et al. 1999; Hammah et al. 2004; Read \& Stacey 2009; Wei et al. 2009). With this approach, the shear strength of the simulated rock mass and joints is incrementally reduced until instability occurs. The factor by which the strengths must be reduced to cause the instability, called the critical strength reduction factor (critical SRF), is analogous to an FoS calculated in SLIDE3. Critical SRF values were obtained for numerous variations of the RS2 model, mostly targeted at evaluating the influence of BD-1 strength parameters below $646 \mathrm{~m}$ elevation, groundwater conditions, and strain softening assumptions. Selected informative cases are presented in Table 3.

Table 3 Factor of Safety and critical strength reduction factor values

\begin{tabular}{|c|c|c|c|}
\hline RS2 & & & SLIDE3 \\
\hline Case & BD-1 joints & Critical SRF & FoS \\
\hline \multirow{3}{*}{$\begin{array}{l}\text { No strain softening, } \\
\text { dry conditions }\end{array}$} & No BD-1 joints & 4.9 & 4.8 \\
\hline & $\begin{array}{l}\text { Strong BD-1 ubiquitous joints ( } 40^{\circ} \text { friction, zero } \\
\text { cohesion) }\end{array}$ & 2.6 & 2.7 \\
\hline & $\begin{array}{l}\text { Weak BD-1 ubiquitous joints ( } 30^{\circ} \text { friction, zero } \\
\text { cohesion) }\end{array}$ & 2.1 & 1.3 \\
\hline \multirow[t]{3}{*}{$\begin{array}{l}\text { Strain softening, } \\
\text { dry-wet conditions }\end{array}$} & $\begin{array}{l}\text { Strong } B D-1 \text { joints }\left(40^{\circ} \text { peak friction, } 34^{\circ}\right. \\
\text { residual friction, zero cohesion) }\end{array}$ & $1.7-1.4$ & 1.11 \\
\hline & $\begin{array}{l}\text { Slightly weakened BD- } 1 \text { joints ( } 35^{\circ} \text { peak friction, } \\
29^{\circ} \text { residual friction, zero cohesion) }\end{array}$ & $1.5-1.2$ & 1.04 \\
\hline & $\begin{array}{l}\text { Weak BD- } 1 \text { joints }\left(30^{\circ} \text { peak friction, } 24^{\circ} \text { residual }\right. \\
\text { friction, zero cohesion) }\end{array}$ & $1.2-0.95$ & 0.97 \\
\hline
\end{tabular}

In the case the strain softening has not been considered, the critical SRF produced closely matching the FoS result from an equivalent SLIDE3 except the case of the weak BD-1 ubiquitous joints. Reducing the strength of the BD-1 joints at the toe of the failure mass to the SLIDE3 calibrated strength ( $30^{\circ}$ friction, zero cohesion) produced a critical SRF of 2.1, substantially higher than the $1.3 \mathrm{FoS}$ calculated in the equivalent dry, calibrated 
SLIDE3 model. The discrepancy in results may be in part a result of the $+/-10^{\circ}$ anisotropic 'window' used in SLIDE3 to represent the BD-1 joints, which allows freedom for the slip surface to align with the most adverse orientation, versus the fixed orientation of ubiquitous joints used in RS2. This again reinforces the potential sensitivity of slope stability to local variations in structural orientations.

It is commonly assumed that once yielding of a rock mass or joint occurs, the 'residual' strength of that rock or joint will be less than its peak strength before yielding. In a finite element model (and in reality), localised yielding within a slope may occur without rendering the slope unstable and for this reason, analysing a model using peak strengths without considering the potential for strain-softening could be non-conservative. Strain-softening behaviour via reduced residual strength parameters was thus introduced in RS2 models. Residual friction angles assumed in RS2 for joints (BD-1) and foliation discontinuities in IF and QR were estimated from the results of direct shear testing summarised in (Piteau Associates Engineering Ltd 2016), which showed a decrease in average friction angle from $38.5^{\circ}$ (peak) to $32^{\circ}$ (residual). In all cases, residual cohesion was assumed to drop to zero (if not set to zero already). No rock mass strain-softening was considered; only post-yield joint strengths were reduced. The results of RS2 models incorporating strain-softening behaviour produced a critical SRF considerably reduced from the critical SRF in the equivalent model without strain softening.

As a final exercise, groundwater was incorporated in RS2. A phreatic boundary representing a near-surface groundwater table was developed and applied to all rock units and joints involved in the failure. This was intended to approximate the effect of the 0.3 Ru coefficient applied in SLIDE3 in the weak QR-IF contact and in the toe of the slope below 646 m elevation. RS2 'wet' model cases produced a critical SRF reduced from the equivalent dry model. The final model produced a critical SRF of 0.95 , reduced from 1.2 in the equivalent dry model. These results align well with the results of the equivalent calibrated SLIDE3 model (FoS 1.3 dry, 0.97 wet).

Figure 9 depicts the critical SRF state of the RS2 case 10 final model showing contours of maximum shear strain. The contact between $Q R$ and IF forms a significant portion of the upper failure surface and the sub-horizontal BD-1 joint set forms the lower portion of the failure surface. Figure 10 depicts the critical SRF state of the RS2 case 10 final model showing contours of total displacement.

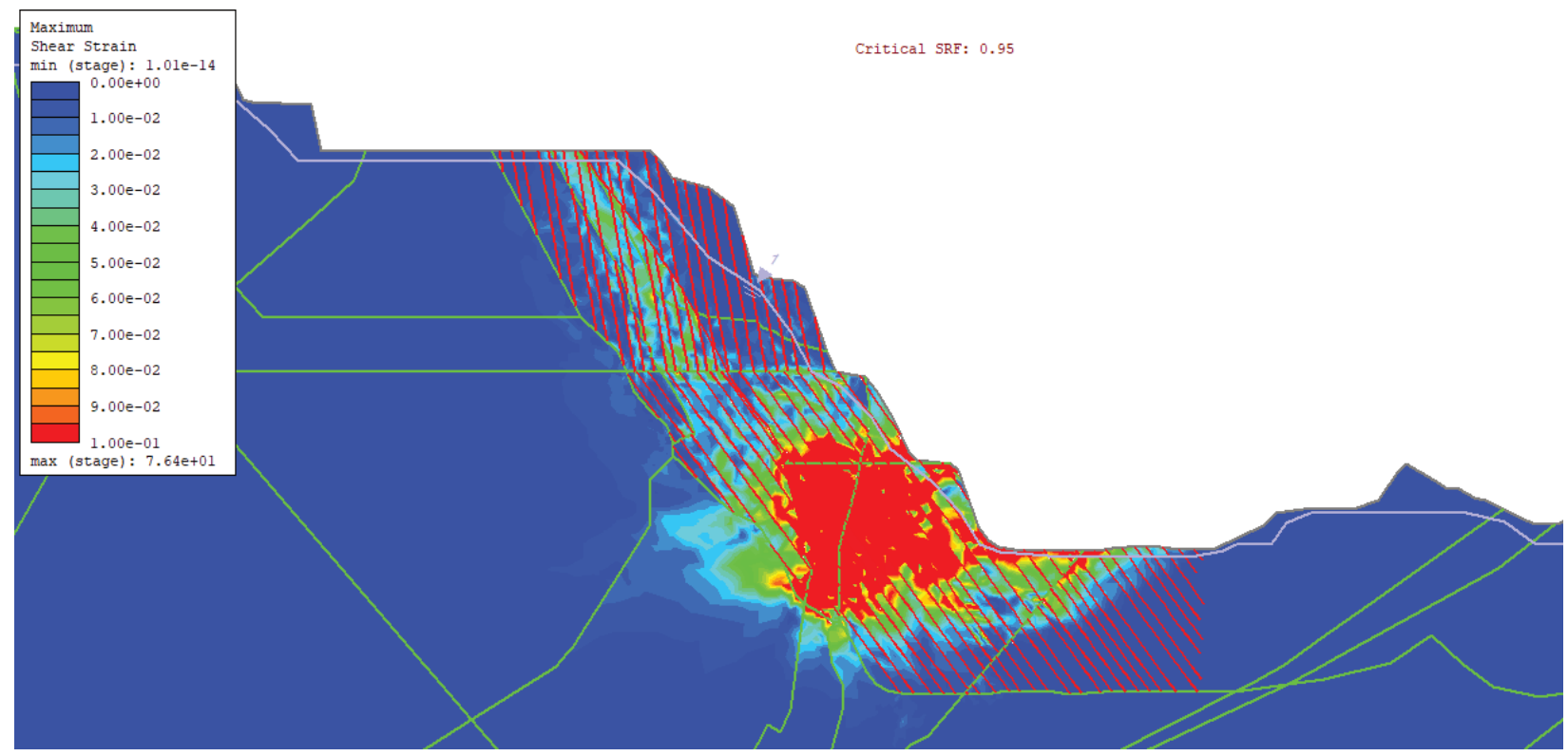

Figure 9 Critical strength reduction factor for RS2 case 10 final model (maximum shear strain) 


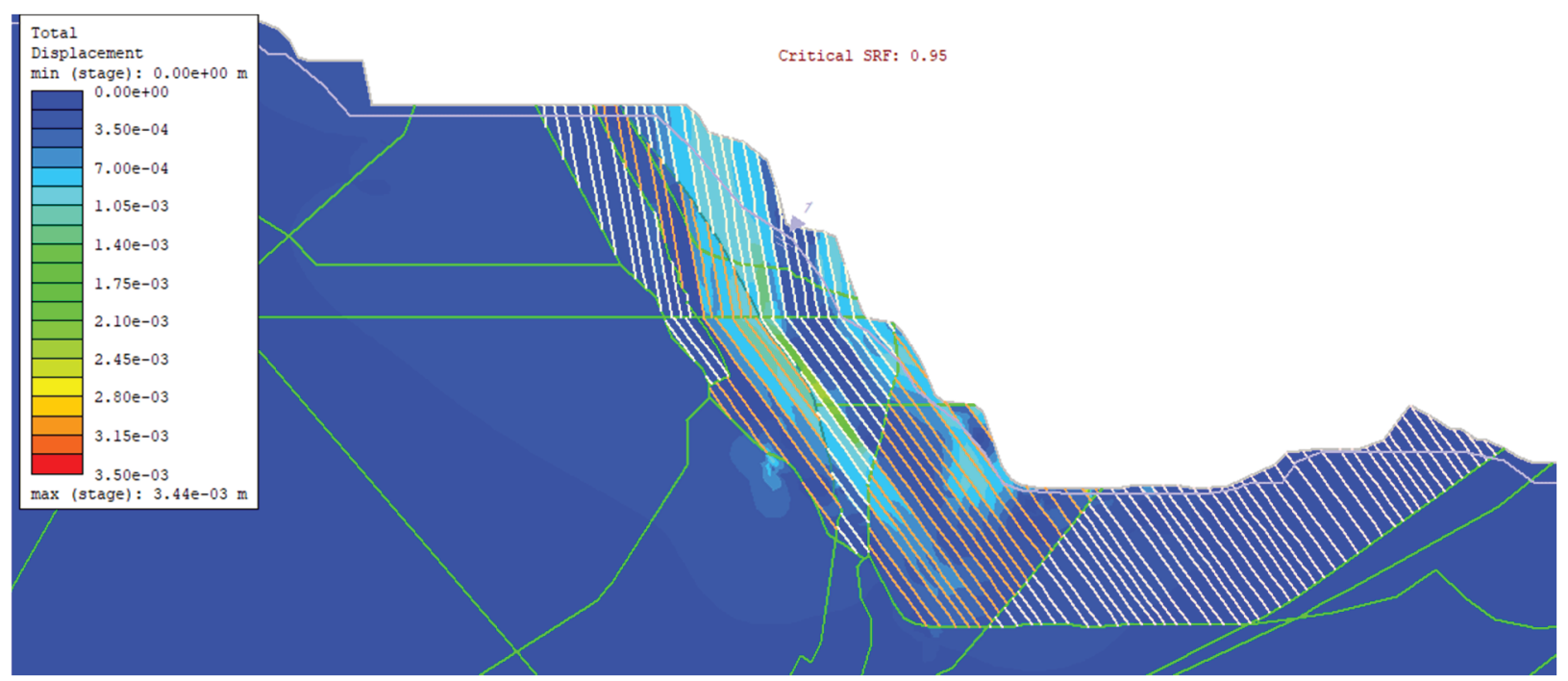

Figure 10 Critical strength reduction factor for RS2 case 10 final model (total displacement)

\section{Discussion}

The presence of a continuous and very weak BD-1 set (or equivalent) was critical to the calibration of the SLIDE3 model but is not clearly supported by domain characterisation data and would require a site-specific investigation to confirm. As noted by Piteau Associates Engineering Ltd (2016), localised variation in structural conditions is likely within this folded geological environment. It is possible that the local orientation of QR foliation continues to rotate (fold) with depth, to daylight at the toe of the failure and provide the necessary toe weakness in place of a weakened BD-1 set (such variation could also contribute to the differences between observed and modelled failure extents). Low strength along locally folded foliation may be more easily justifiable along BD-1 cross joints given the observed continuity and planarity of the foliation discontinuities in existing wedge failures. However, confirming this folding would require very localised assessment of the structural geology which was beyond the scope of this study. In either case, the model results indicate that the toe of the failure mass must be substantially weakened in the direction of breakout in order to produce FoS values indicating instability over the observed failure extents.

Although both SLIDE3 and RS2 models produced similar FoS results with similar inputs, the significant differences in these two model scenarios must be noted. Perhaps most importantly, these include differences in geometry (2D versus 3D), and in calculation method (numerical stress-strain simulation versus limit equilibrium calculation). Further, achieving the targeted SRF values in RS2 required the inclusion of reduced residual strength parameters, which were not incorporated in SLIDE3 models which produced similar FoS results (post-yield behaviour is not simulated in a limit equilibrium calculation). Unlike in RS2, joint sets in the SLIDE3 models are represented as anisotropic strength windows, with ranges of $+/-10^{\circ}$ around the average joint set orientation. This allows for the failure surface to exploit the joint set weakness at whichever orientation within the defined range that results in the least stable slip surface. This flexibility allowed in SLIDE3 (particularly on the BD-1 joint set) likely contributed to the lower FoSs achieved without the use of reduced residual strength parameters. Considering the uncertainty assumed local structural orientations and strengths, both calibrations are considered reasonable and the differences between them underscore the importance of accounting for potential variability in structural orientations and strengths in-pit wall design.

\section{Conclusion}

An attempt has been made to calibrate simplified models developed in SLIDE3 and RS2 to reproduce the 2018 instability in the open pit studied. One of the purposes of this study was to develop an understanding of the mechanisms and key sensitivities, with regards to stability, which may have been involved in the open pit failure, with the intent that this understanding may be applicable to the design and stability evaluation of other pit walls in the mine site. 
Through experimentation, it was found that reproducing the instability of the highwall was critically sensitive to the local structural characterisation. In order to produce FoSs (or critical SRF) approaching the target of 1.0 , it was necessary to reduce the strength of controlling structural features and add groundwater pressures to the areas bounding the failure. In the case of the open pit failure studied, base models were developed using characterisation data from a much broader domain than the immediate vicinity of the failure, and these initial models did not reproduce the observed instability. The modelled solution was to significantly weaken the sub-horizontal BD-1 joint set to reduce FoS and initiate toe breakout, but other unknown and localised contributing factors could have been involved. In particular, it is possible that localised rotation (folding) of the weak QR foliation with depth could have contributed to the failure mechanism, but this local variation would not be captured in a domain-scale structural characterisation.

To address this potential variability in general, it is important that structural characterisations at the design and operation stage are carried out with a strong understanding of the broader geological environment and orebody genesis, which will aid in interpolating geological and structural trends between drillholes. Impacts of fold structures, for instance, on local orientation of foliation discontinuities could be significant to slope design. Where structural domains can be only broadly defined and no additional data can be collected, sensitivity analyses on key structural orientations would be appropriate. In addition, the frictional strengths of discontinuities which are interpreted to have controlled the highwall failure are highly sensitive to the presence of groundwater pressures. Understanding the hydrogeological regime, its seasonal variation, and the effects of slope drainage are important to any pit wall design.

\section{Acknowledgement}

The authors thank ArcelorMittal Mining Canada and Golder Associates for their support of this project.

\section{References}

Coggan, JS, Stead, D \& Eyre, JM 1998, 'Evaluation of techniques for quarry slope stability assessment', Proceedings of the 10th Extractive Industry Geology conference, Exeter.

Dawson, EM, Roth, WH \& Drescher, A 1999, 'A slope stability analysis by strength reduction', Geotechnique, vol. 49, no. 6, pp. 835-840.

Duncan, JM \& Wright, SG 2005, Soil strength and slope stability, John Willey and Sons Inc, Hoboken.

GroundProbe 2018, SSR340XT Failure back-analysis, technical report.

Hammah, RE, Curran, JH, Yacoub, TE \& Corkum, B 2004, 'Stability analysis of rock slopes using the Finite Element Method', Proceedings of the ISRM Regional Symposium EUROCK 2004 and the 53rd Geomechanics Colloquy, Austrian Society for Geomechanics, Salzburg.

Hoek, E, Carranza-Torres, C \& Corkum, B 2002, 'Hoek-Brown Failure Criterion - 2002 Edition', Proceedings of the 5th North American Rock Mechanics Symposium and the 17th Tunnelling Association of Canada Conference, Toronto, pp. 267-293.

Janbu, N 1973, 'Slope stability computations', in RC Hirschfield \& SJ Poulos (eds), Embankment-Dam Engineering, John Wiley \& Sons Inc., New York, pp. 47-86.

Jing, L 2003, 'A review of techniques, advances and outstanding issues in numerical modelling for rock mechanics and rock engineering', International Journal of Rock Mechanics \& Mining Sciences, vol. 40, pp. 283-353.

Kabuya, JM \& Henriquez, F 2017, Phase 1 south east instability assessment - preliminary results, internal technical report.

Martin, CD \& Carew, JT 1986, 'Application of a rock buttress to design of slope at Cassiar Mine', CIM Bulletin, vol. 79 , no. 896.

Martin, D \& Stacey, P 2018, Guidelines for open pit slope design in weak rocks, CSIRO Publishing, Carlton.

Piteau Associates Engineering Ltd 2016, Geotechnical slope stability analysis and design for the 2015 pit mine plan, technical report.

Read, J \& Stacey, P 2009, Guidelines for open pit slope design, CSIRO Publishing, Carlton.

Rocscience Inc. 2019a, SLIDE3, computer software, Rocscience, Toronto, https://www.rocscience.com/software/slide3

Rocscience Inc. 2019b, RS2, computer software, Roscscience, Toronto, https://www.rocscience.com/software/rs2

Stead, D, Eberhardt, E \& Coggan, JS 2006, 'Developments in the characterization of complex rock slope deformation and failure using numerical modelling techniques', Engineering Geology, vol. 83, pp. 217-235.

Wei, WB, Cheng, YM \& Li, L 2009, 'Three-dimensional slope failure analysis by the strength reduction and limit equilibrium methods', Computers and Geotechnics, vol. 36, pp. 70-80.

Wyllie, DC \& Mah, CW 2004, Rock Slope Engineering: Civil and Mining, 4th ed., Taylor \& Francis Group, New York. 
